\title{
Development and validation of the smart classroom inventory
}

\author{
Baoping $\mathrm{Li}^{1 *}$, Siu Cheung Kong ${ }^{2}$ and Guang Chen ${ }^{1}$
}

\author{
* Correspondence: \\ libp@bnu.edu.cn \\ ${ }^{1}$ School of Educational Technology, \\ Beijing Normal University, Beijing, \\ China \\ Full list of author information is \\ available at the end of the article
}

\begin{abstract}
This paper discusses the development and validation of the Smart Classroom Inventory (SCl). The $\mathrm{SCl}$ is derived from existing technology integration learning environment instruments, including TROFLEI, TICI and CCEI (ergonomic). To accurately describe the features of smart classroom, the factors of flexibility, learning data, learning experience are added to $\mathrm{SCl}$, and the description of information technology usage of some items are also altered to fit the smart classroom environment. More than 64011 to 15 years old students validated the instrument, revealing ten scales: Physical Design, Flexibility, Technology Usage, Learning Data, Differentiation, Investigation, Cooperation, Students Cohesiveness, Equity, and Learning Experience. Cronbach's alpha coefficient is 0.92 and 0.94 for the entire questionnaire in Actual and Preferred forms respectively. The results of EFA and CFA prove SCl to be a parsimonious instrument for assessing the smart classroom learning environment. In assessing Actual and Preferred learning environments, $\mathrm{SCl}$ results indicated that there are significant differences in all of the ten factors. Students' perception of factors of Differentiation, Flexibility, Technology Usage, and Learning Data are the largest four actual-preferred discrepancies within the smart classroom learning environment. These suggest the importance of innovative application of the current information equipment, and schools should pay more attention to satisfying the students' personalized learning demands. The differences between the gender and between the school settings indicate that smart classroom should integrate both the technology and the humanities factors into the design and application of smart classroom, as well as design multi-level learning activities to satisfy the choices of different age students.
\end{abstract}

Keywords: Smart learning environment; Smart classroom; Technology integration learning environment; Instrumentation

\section{Introduction}

Now, many classrooms have connected with Internet and equipped with variety advanced information devices, such as tablet PCs and interactive whiteboards. The type of classroom is named as smart classroom, intelligent classroom, or classroom in the future. With the support of technologies, the smart classrooms become the places where teachers and students could practice rich and immersive teaching and learning experiences that they have never had before.

Many researches have explored the relationship between learning skills, learning outcomes and learning environments (Ramsden 1979, 1991; De Corte et al. 2004; Grady and Fisher 2008; Chang et al. 2011). As a burgeoning learning environment, the study

(c) 2015 Li et al.; licensee Springer. This is an Open Access article distributed under the terms of the Creative Commons Attribution License (http://creativecommons.org/licenses/by/4.0), which permits unrestricted use, distribution, and reproduction in any medium, provided the original work is properly credited. 
was interested in exploring the relationship between smart learning environments and students' learning skills that were critical in the $21^{\text {st }}$ century.

\section{Background and literature review}

\section{Learning environment and the smart classroom}

The learning environments in schools were described as "a classroom or school climate, environment, atmosphere, tone, ethos, or ambience" (Fraser 1994). The classroom environment is not only a place to house books, desks, and materials, but also a place where teaching and learning activities occur. With a careful design, all the elements in the classroom add a significant dimension to students' educational experience, supporting and strengthening students' desire to learn (Loughlin and Suina 1982).

Ramsden (1979) indicated that the teachers' understanding of students and tutors' teaching effectiveness are important to students' learning; and the study emphasized the supportive learning atmosphere for students. Lizzion et al. (2002) found perceptions of a good teaching environment influence students towards deep approaches to studying; and perceptions of teaching environments influence learning outcomes both directly (perceptions of outcomes) and indirectly (perceptions of approaches to outcomes). Rahman and Mokhtar (2012) found two learning environment elements namely "learning community" and "assessment" had a direct relationship, and three other elements namely "clear objective", "good teaching" and "learning resources" were indirectly related to generic skills through learning approach. These researches supported the social cognitive theory's hypothesis that students' generic skills result from their interaction with their environments.

In the contemporary information society, the low literacy skills such as reading, writing, calculating would be replaced by high literacy such as critical thinking, communication, sharing and complex problem solving. As the result of above researches indicated that the new skills learning not only supported by the innovation on learning contents and learning approaches, but also supported by the learning environments. Hall et al. (2004) measured the change of students' deep and surface learning approaches; based on the data they provided preliminary evidence of the ability of changing students' approaches to learning through specific changes to the learning environment. So it is necessary to research the classroom environment in the information society; now smart classroom environment has been researched by many countries. For example, the smart school project in Malaysia, the technology-rich classroom programs in America, and Nanhu primary school's future classroom project in Taiwan.

At the beginning, the term smart classroom is for distinguishing from the term "computer classroom". It often refers to the classroom equipped with interactive whiteboards to support real-time interaction between teachers and students and carry out teaching and learning activities (Zhao 2008). But now, accompanying with the development of emerging technology, like wireless communication technology, context awareness technology, massive data mining and analysis, and smart interactive technology, smart classroom always represents the technology-rich classroom, i-classroom or future classroom.

Some programs were held to research how the smart classroom should be and what will happen to teaching and learning in the smart classroom. University of Minnesota's new, technology-enhanced learning spaces project constructed the Active Learning 
Classrooms (ALCs) (Whiteside et al. 2010). In the ALCs, the classrooms featured a number of large circular tables, each of which accommodated nine students and had three laptop computer connections to large LCD screens to facilitate collaborative work. The ALCs featured 360-degree glass marker boards around the edges. Technology Rich Classrooms Program in Kansas is funded through the competitive portion of Title IID. The Minimum Classroom Equipment include 2:1 student to computer ratio (laptops or desktops), interactive whiteboard, media projector, digital still camera, printer, scanner, Internet access and software to support instruction and curriculum projects (The Free Library 2007). Although the equipment and appearance of the above classrooms are different, they are all aim to build an open, interactive, flexible and media-rich instruction environment to support the individual or collaborative learning in schools.

\section{The features of smart classroom}

With content analysis to the journal articles about smart learning environments from 2001 to 2013, Li and Kong (2014) indicated that the most attractive characteristic of the smart classroom is its integration of all kinds of interactive technologies, data analysis techniques, and context-aware technologies and devices to support the digital intelligence teaching and learning activities.

Hwang et al. (2010) used PDA and RFID reader and tag construct a context-aware ubiquitous learning environment, and implemented it for the "butterfly and ecology" unit of a fourth-grade natural science course in Taiwan. They also developed the decision-tree-oriented mechanism to enable the learning environment give digital guidance to students to observe and classify real-world objects in the learning activities of natural science courses. Yau et al. (2003) applied the situation-aware PDA's orientation function in students' group discussion and learning resource sharing in order to increase the level and quality of interactions between students and the instructor in a classroom. Using intelligent agents and 3D avatars, Lemmon et al. (2012) allowed students to interact with avatars, participate in the virtual world to conduct experimental investigation, and collect and analyze data. Based on the data mining technique, Lin et al. (2013) developed a personalized creativity learning system to provide personalized learning paths for optimizing student' performance of creativity. Their research suggested that data mining technique can be a good vehicle for providing adaptive learning.

These researches for smart classroom show us that with the help of smart technology, inquiry learning, collaborative learning, group learning, mobile learning, and ubiquitous learning are emerging (Lin et al. 2010). All the pedagogical cases highlight the adaptive abilities of the smart classroom which could support the individual learning, and underline the interactive supports which were supported by all type of the smart technologies (Silva and Restivo 2009; Yang and Lin 2010). In a smart classroom environment, it will be easier to stimulate students' learning motivation, promote students' active learning behavior, and achieve good learning performance (Liu et al. 2011).

This study summarizes the features of smart classroom. 1) The smart classroom is a technology-rich, physical and virtual combined learning environment which has the ability of context awareness and can adjust their environmental parameters like light and temperature automatically. 2) The smart classroom could provide the learning contents, interaction support, and constructive learning tools for all type of the teaching 
and learning activities, including personalized learning, group learning, inquiry learning, collaborative learning, mobile learning, and virtual learning. The smart classroom conducive to student-centered learning gives students the adaptive learning support for active learning and constructive learning activities. 3) The smart classroom has the ability to store, collect, compute, and analyze the massive data of learners to do the optimized pedagogical decisions. 4) The smart classroom is an open learning environment to bring the students to an authentic learning context. It can stimulate students' learning motivation, engage students' creation, and give students hands-on learning experience effectively.

\section{The inventories for measuring technology integration classroom}

Trickett and Moos (1973) described a schema for describing the classroom environment in three dimensions: system maintenance and change, personal development, and relationship. The integration of technologies into the classroom also made some change in the three dimensions.

In the past industrial era, the instruction technologies such as lantern slides, projector, film and television set were applied in the classrooms. Those kinds of technologies can make the teachers' instruction content spread wider, can make the teachers' voice louder, and even can record some audio and visual information which would be learned without teachers. The audio-visual technologies promoted the classroom environment coming into the electronic era. They become an information transfer medium between teachers and students and make the teacher-centered pedagogical activities more robust and more efficient.

Since early 1990s, the computers were used in the classrooms. Carter (1990) confirmed the new technology would construct a new learning environment. Newhouse (2001) considered the computers increase the complexity of the traditional education relationship, for "all elements of the traditional classroom learning environment needing to interact with both the hardware and software". Differed from the audio-visual technology, the mutual interactive abilities of the computers are able to instruct the students' learning activities, and have the possibility to make student-centered classroom to be reality.

The computer changes the physical appearance of classroom environment, the teaching and learning theory and practice, as well as the relationship between teacher and student. The computer replaces some works of teachers; it can give students learning information, can communicate with students and make diagnose for students' learning activities. Based on its powerful interaction and computation abilities, the computer has the possibility to give each student customized rather than those standardized learning procedure that in the traditional teacher-centered classroom. In order to accurately describe the new characteristic, some inventories for the computerized classroom were developed.

Aldridge et al. (2004) developed the Technology-Rich Outcomes-focused Learning Environment Inventory (TROFLEI). It includes 8 dimensions namely student cohesiveness, teacher support, involvement, investigation task orientation, cooperation, equity, differentiation, computer usage, and young adult ethos. Wu et al. (2009) developed the Technology Integrated Classroom Inventory (TICI), including technological enrichment, 
inquiry learning, equity \& friendliness, student cohesiveness, understanding \& encouragement, competition \& efficacy, audiovisual environment, and order. Maor and Fraser (1996) developed "Computerized Classroom Environment Inventory". It includes investigation, open-endedness, organization, material environment, and satisfaction. Based on the application of portable computers in the secondary school math class, Newhouse et al. (1998) developed the New Classroom Environment Instrument (NCEI), including 8 dimensions namely involvement, affiliation, teacher support, group work, competition, order and organization, teacher control, innovation. Each dimension includes 7 items.

Zandvliet et al. (1999) focused on the physical appearance of computerized classroom, he constructed the Computerized Classroom Ergonomic Inventory to describe the physical environment and equipment of the classroom, including workspace environment, computer environment, visual environment, spatial environment, and air quality.

These existing inventories like TROFLEI, TICI, and NCEI have proved to be effective tools for assessing computerized classroom. Been looked as the advanced stage of computerized classroom (Huang et al. 2012), these inventories could be used to assess smart classroom. However, with integration of emerged information technologies, several measurements such as flexibility use of smart classrooms, adaptive learning support, and offering of authentic learning experience are more significant in the smart classroom environment. They have not been considered in the existing inventories. The exclusion of such distinct features will obscure the characteristics of smart classroom to be fully reflected. The aim of the study is to develop a comprehensive instrument focusing on all the characteristics of smart classroom, as well as addressing the limitation of previous inventories.

\section{Research design and methodology}

This study started to develop the smart classroom inventory by initially gathering salient scales from existing inventories. The smart classroom is the technology-rich classroom, so the study chose the Technology-Rich Outcomes-Focused Learning Environment Inventory (TROFLEI), and Technology Integrated Classroom Inventory (TICI) to develop the smart classroom inventory. Considering the smart classroom has much change in spatial design and technology equipment, the study also chose Computerized Classroom Ergonomic Inventory (CCEI) to construct the smart classroom inventory.

This study chose specific scales from various existing instruments in relation to the features of smart classroom. For example, TROFLEI's computer usage scale and TICI's technological enrichment scale measure the application of computer for teaching and learning activities were selected. CCEI's workspace environment scale describing the spatial arrangement of classroom was also selected. At last, eight scales namely workspace environment, spatial environment, computer usage, differentiation, investigation, cooperation, learner's cohesiveness, and equity are selected from the three inventories (Li et al. 2014).

The items of each collective scale were added into the item pool. If there was more than one scale with identical meaning, only one was retained. For example, TROFLEI's investigation and TICI's inquiry learning have similar meaning; this study selected the TROFLEI's investigation items into the item pool. For some critical features of smart classroom, such as flexibility use of smart classroom, learner-data-based pedagogical 
decision-making and adaptive learning support, and authentic learning experience were not included. The study added the dimension of "flexibility", "learning data", and "learning experience" into the item pool. By this way, an original inventory which contains 10 dimensions and 63 items was derived. The detailed information can be found in the pilot research of Li et al. (2014).

Discussed with two experts in the domain of educational technology and 3 teachers in primary and secondary schools with rich teaching experiences in e-learning, 3 items are deleted. Fifteen students aged from 12 to 14 in primary and secondary schools had the pre-tests of the second version 60 -item scale, with 2 items were revised. Then the smart classroom inventory was determined as shown in Table 1.

\section{Method}

\section{Sample}

In China, many schools usually choose students in Grade 4 to Grade 8 to carry out the pilot study towards e-learning, so 436 students aged from 11 to 15, in 16 computer applying classes of 10 primary and secondary schools in metropolitan area of Shenzhen and Beijing, China were involved. The demographics of the students are shown in Table 2. These 10 schools all have put e-learning into practice for more than one decade; and the information infrastructure are well built. All the students have the experience of learning in the 1 to 1 learning environment with tablet PCs and wireless network.

Table 1 Description of the scales of Smart Classroom Inventory (SCI)

\begin{tabular}{|c|c|c|}
\hline Scale name & Scale description & Sample items \\
\hline Physical design & $\begin{array}{l}\text { The extent to which the spatial area, furniture } \\
\text { equipment, and information technology } \\
\text { infrastructure of smart classrooms. }\end{array}$ & $\begin{array}{l}\text { I have adequate workspace for putting } \\
\text { textbooks, tablet PCs and other resources. }\end{array}$ \\
\hline Flexibility & $\begin{array}{l}\text { The extent to which the comfortable } \\
\text { support for users by classroom } \\
\text { environment. }\end{array}$ & $\begin{array}{l}\text { The classroom can be a theater, a group } \\
\text { working place or other scenes for different } \\
\text { learning purposes. }\end{array}$ \\
\hline Technology usage & $\begin{array}{l}\text { The extent to which students use } \\
\text { information technology as a tool to learn } \\
\text { and to access information. }\end{array}$ & $\begin{array}{l}\text { I deal with my assignments using } \\
\text { computer or other digital devices. }\end{array}$ \\
\hline Learning data & $\begin{array}{l}\text { The extent to which the information } \\
\text { technology was used to acquire and } \\
\text { compute the learning data of the users. }\end{array}$ & $\begin{array}{l}\text { I can find out my learning history, like my } \\
\text { homework, and discussions in the last semester } \\
\text { using computers or other digital devices. }\end{array}$ \\
\hline Differentiation & $\begin{array}{l}\text { The extent to which teachers cater for } \\
\text { students differently on the basis of ability, } \\
\text { rates of learning and interests. }\end{array}$ & I can learn at my own pace. \\
\hline Investigation & $\begin{array}{l}\text { The extent to which skills and processes of } \\
\text { inquiry and their use in problem solving } \\
\text { and investigation are emphasized. }\end{array}$ & I carry out investigations to test my ideas. \\
\hline Cooperation & $\begin{array}{l}\text { The extent to which students cooperate } \\
\text { with one another on learning tasks. }\end{array}$ & $\begin{array}{l}\text { I can cooperate with somebody outside } \\
\text { the classroom through Internet when } \\
\text { doing assignment work. }\end{array}$ \\
\hline Students cohesiveness & $\begin{array}{l}\text { The extent to which students know, help } \\
\text { and are supportive of one another. }\end{array}$ & I am friendly to members of the class. \\
\hline Equity & $\begin{array}{l}\text { The extent to which students are treated } \\
\text { equally by the teacher. }\end{array}$ & $\begin{array}{l}\text { I am treated in the same way as other } \\
\text { students in this class. }\end{array}$ \\
\hline Learning experience & $\begin{array}{l}\text { The extent to which students' satisfaction } \\
\text { and some special learning experience in } \\
\text { smart classroom. }\end{array}$ & $\begin{array}{l}\text { The devices and software help me to get } \\
\text { hands-on experience with the learning } \\
\text { objects or learning context. }\end{array}$ \\
\hline
\end{tabular}


Table 2 The demographics of the students in the survey

\begin{tabular}{llllllllll}
\hline Gender & & School & \multicolumn{3}{c}{ Age } & \multicolumn{3}{c}{ City } \\
\hline Female & Male & Primary & Secondary & 11 & 12 & 13 & $>=14$ & Shenzhen & Beijing \\
211 & 225 & 302 & 134 & 77 & 177 & 141 & 41 & 252 & 184 \\
\hline
\end{tabular}

\section{Translation}

The SCI, which had been developed in English, had to be translated into Chinese. As all the researchers have bilingual education background, a brief back-translation process was conducted. First, the SCI was translated from the source language of English to the target language of Chinese. A draft of the Chinese version was prepared by the researchers and revised by other three colleagues if they did not agree with the translations. All of these colleagues have PhDs in Education from USA or Hong Kong universities and work at colleges of education in different universities in Hong Kong and mainland China. Then three individuals who were not involved in the research, and did not read the English version of the SCI before were asked to translate the Chinese version of SCI back into English. There were no major discrepancies between the different versions, or between the original SCI in English and the version that resulted from the back-translation. Finally, the researchers assessed and discussed the responses and the final Chinese version of SCI was prepared.

Test

With the approval of the school administration, a questionnaire survey was conducted with the targeted students. The questionnaire contained a cover sheet for recording the survey details, and a student questionnaire. The student questionnaire included three sections: the participants' basic information, the actual form for classroom perception questions, and the preferred form for classroom perception questions. The actual classroom questions asked about the current learning environment; and the preferred classroom questions asked about the ideal learning environment of the students. All questions were worded using a positive scoring direction and measured using a 5-point Likert-type scale with anchors from almost never (scored as 1) to almost always (scored as 5). Twenty-seven questionnaires were discarded due to incomplete data. Finally 409 students' effective responses were used for data analysis.

\section{Result}

\section{Verification of the instruments}

All the data were analyzed by SPSS 21.0. The results of Cronbach's alpha coefficient for each scale and exploratory factor analyses (EFA) on the Actual and Preferred Forms of the SCI are shown in Table 3. A principal components analysis with varimax with Kaiser Normalization rotation yielded 10 factors for the actual form of SCI. Items with factor loading values below 0.4 on their own scales or greater than 0.4 on each of the other scales were eliminated.

The result of correlation of a scale with the remaining scales for each of the 10 scales for actual form is shown in Table 4. The correlations between scales for the Actual form ranged from 0.14 to 0.65 . It suggested that most of the SCI scales had adequate discriminant validity for use in its Actual forms. 
Table 3 Exploratory factor analysis and Cronbach's alpha values for both forms of the ten factors of the smart classroom survey

\begin{tabular}{lll}
\hline Factors and Items & $A^{\mathbf{a}}$ & $P^{\mathbf{b}}$
\end{tabular}

Factor1: Physical design (PD), Actual $a=0.61$, Preferred $a=0.84$

I have adequate workspace for putting textbooks, tablet PCs and other resources. $\quad 0.540 .76$

I can easily read the content on the screen in any lighting conditions. $\quad 0.73 \quad 0.74$

In the classroom I can see the teacher's instruction and the classmate's presentation all together. $\quad \begin{array}{lll}0.75 \quad 0.72\end{array}$

The classroom is quiet; I can hear what the teacher and other students say clearly. $\quad 0.45 \quad 0.74$

Factor2: Flexibility (FL), Actual $a=0.62$, Preferred $a=0.57$

The classroom is climate controlled with localized temperature and humidity controls.

The classroom can be a theater, a group working place or other scenes for different learning purposes.

I can only access into school using my authentication.

0.690 .53

Factor3: Technology usage (TU), Actual $a=0.85$, Preferred $a=0.84$

I deal with my assignments using computer or other digital devices.

$0.82 \quad 0.81$

I submit my assignments to teachers using computer or other digital devices.

0.760 .76

I obtain the information related to learning with computers or other digital devices.

0.800 .56

I use the computer to read lesson notes prepared by the teacher.

0.790 .52

Factor4: Learning data (LD), Actual $a=0.75$, Preferred $a=0.62$

My parents can acquire my learning status in school from some apps or digital communication platforms easily.

I can find out my learning history such as my homework, and discussions using computers or other digital devices.

I have my own learning e-portfolio.

Factor5: Differentiation (DI), Actual $a=0.80$, Preferred $a=0.85$

I have the possibilities to learn at my own pace in my class.

I have the possibilities to choose the learning tasks to be completed in my class.

$0.70 \quad 0.79$

I have the possibilities to choose the different materials for learning in my class.

0.690 .80

I have the possibilities to choose the different assessment for learning in my class.

Factor6: Investigation (IN), Actual $a=0.85$, Preferred $a=0.90$

I have the possibilities to carry out investigations to test my ideas in my class.

$0.66 \quad 0.74$

I am asked to provide evidence that supports my views in my class.

I have the possibilities to carry out investigations to answer questions coming from teachers or discussions in my class.

I have the possibilities to find out answers to questions by doing investigations in my class.

Factor7: Cooperation (CO), Actual $a=0.77$, Preferred $a=0.82$

I have the possibilities to cooperate with other students when doing assignment work in my class.

I have the possibilities to cooperate with somebody outside the classroom through Internet when doing assignment work in my class.

I have the possibilities to discuss with virtual partners when doing assignments in the classroom.

Factor8: Students cohesiveness (SC), Actual $a=0.77$, Preferred $a=0.84$

I make friends among students in the class.

I am friendly to members of the class.

I help other class members.

Factor9: Equity (EQ), Actual $a=0.82$, Preferred $a=0.80$

The teacher takes a personal interest in me. 
Table 3 Exploratory factor analysis and Cronbach's alpha values for both forms of the ten factors of the smart classroom survey (Continued)

\begin{tabular}{ll}
\hline The teacher considers my feelings. & 0.790 .81 \\
I am treated in the same way as other students in this class. & 0.700 .51 \\
$\begin{array}{l}\text { Factor10: Learning experience (LE), Actual } a=0.74 \text {, Preferred } a=0.79 \\
\text { I am motivated by the multi-media learning contents. }\end{array}$ & 0.760 .81 \\
The devices and software are easy to use. & 0.700 .70 \\
The devices and software help me to get hands-on experience with the learning objects & 0.690 .61 \\
or learning context. & \\
\hline
\end{tabular}

Note. A: Actual form, P: Preferred form. Actual form total variance explained: $65.21 \%$, overall alpha: 0.92 . Preferred form total variance explained: $71.30 \%$, overall alpha: 0.94 .

Thus, as shown in Table 3, a total of 36 items in 10 factors were extracted, with the KMO 0.90 and total accounting for $65.21 \%$ of the explained variance in actual form and KMO 0.92 and total accounting for $71.30 \%$ of the explained variance in preferred form.

Based on the result of EFA, a new survey was conducted to 240 primary and secondary students in Beijing, using the new SCI with 10 factors and 36 items for confirmation factor analyses (CFA) on the Actual and Preferred Forms. The result of CFA for SCI is shown in Table 5. With the exception of Actual form's NFI 0.86 and Preferred form's GFI 0.88 which are very near the recommended values of 0.90 , all fit indices for the measurement model exceeded the recommended values for the respective indices according to common criteria. Altogether, the fit indices indicated that the hypothesized model was well fitted with the data collected and the instrument was provided with construct validity.

\section{Students' perception of smart classroom}

The Mean, Standard Deviation (SD), T-test, and Cohen's d for both Actual and Preferred forms are shown in Table 6. Cohen's $d$ is an effect size used to indicate the standardized difference between two means. In the Actual form, the factor of Students Cohesiveness got the highest score, and the factor of Differentiation got the lowest score. In Preferred form, the factor of Students Cohesiveness also got the highest score,

Table 4 Correlation for actual form of the ten factors of the smart classroom survey

\begin{tabular}{|c|c|c|c|c|c|c|c|c|c|c|}
\hline Factors & PD & $\mathrm{FL}$ & TU & LD & DI & IN & $\mathrm{CO}$ & SC & EQ & LE \\
\hline Physical design & 1 & & & & & & & & & \\
\hline Flexibility & $.38^{* *}$ & 1 & & & & & & & & \\
\hline Technology usage & $.32^{* *}$ & $.41^{* *}$ & 1 & & & & & & & \\
\hline Learning data & $.28^{* *}$ & $.44^{* *}$ & $.40^{* *}$ & 1 & & & & & & \\
\hline Differentiation & $.29^{* *}$ & $.45^{* *}$ & $.42^{* *}$ & $.58^{* *}$ & 1 & & & & & \\
\hline Investigation & $.25^{* *}$ & $.34^{* *}$ & $.24^{* *}$ & $.49^{* *}$ & $.55^{* *}$ & 1 & & & & \\
\hline Cooperation & $.27^{*}$ & $.38^{* *}$ & $.30^{* *}$ & $.48^{* *}$ & $.50^{* *}$ & $.65^{* *}$ & 1 & & & \\
\hline Students cohesiveness & $.27^{* *}$ & $.20^{* *}$ & $.14^{* *}$ & $.14^{* *}$ & $.18^{* *}$ & $.33^{* *}$ & $.37^{* *}$ & 1 & & \\
\hline Equity & $.27^{* *}$ & $.20^{* *}$ & $.19^{* *}$ & $.29^{* *}$ & $.30^{* *}$ & $.38^{* *}$ & $.38^{* *}$ & $.46^{* *}$ & 1 & \\
\hline Learning experience & $.30^{* *}$ & $.27^{* *}$ & $.26^{* *}$ & $.35^{* *}$ & $.36^{* *}$ & $.41^{* *}$ & $.39^{* *}$ & $.37^{* *}$ & $.48^{* *}$ & 1 \\
\hline
\end{tabular}
Note. ${ }^{* *} p<.01$. 
Table 5 Confirmation factor analysis for both forms of the ten factors of the smart classroom survey

\begin{tabular}{lllllllllll}
\hline \multicolumn{1}{l}{} & \multicolumn{1}{l}{ Goodness-of-fit measure } \\
\cline { 2 - 10 } & $\mathbf{X}^{\mathbf{2}}$ & $\mathbf{d f}$ & $\mathbf{X} \mathbf{2} \mathbf{d f}$ & GFI & AGFI & CFI & NFI & TLI & RMR & RMSEA \\
\hline Actual & 672.45 & 615 & 1.09 & 0.90 & 0.88 & 0.99 & 0.86 & 0.98 & 0.08 & 0.02 \\
Preferred & 841.90 & 586 & 1.44 & 0.88 & 0.85 & 0.97 & 0.90 & 0.96 & 0.05 & 0.04 \\
\hline
\end{tabular}

while the factor of Learning Data got the lowest score. Students' perception of all the ten factors has significant difference between Actual and Preferred forms.

As shown in Figure 1, there is a big gap between the students' perception of the current learning environment and the ideal learning environment, especially in the factors of Differentiation, Flexibility, Technology Usage, and Learning Data. Mean for these several factors in Actual form are below average score 3. The gap for factors of Students Cohesiveness and Equity is relative small. The means for the two factors in Actual form are the highest two scores among all the ten factors.

The differences in perception of smart classroom between female and male students

The Mean, Standard Deviation (SD), and T-test for both female and male students' perception of smart classroom in both actual and preferred forms are respectively shown in Table 7 and Table 8.

Except a few scales such as Flexibility in actual form and Investigation in preferred form, the scores in all the other scales of female are higher than those of male. The result indicates that female students have more positive attitude to smart classroom.

In current situation, besides the Learning Data, there are significant gender differences existing in the students' perception of relationships in the classroom, namely Students Cohesiveness, and Equity.

Well in the preferred form, the gender differences also exist in the students' perception of relationships in the classroom, namely Students Cohesiveness, and Equity, as well as in the perception of experience in the classroom, namely Flexibility, and Learning experience.

Table 6 Summary of measurement scales of students' perception of smart classroom for both forms

\begin{tabular}{llllllll}
\hline Factors & Mean & & & SD & & T-test & Cohen's d \\
\cline { 2 - 3 } & Act. & Pref. & & Act. & Pref. & & \\
\hline Physical design & 3.51 & 4.42 & & 0.85 & 1.14 & $-13.62^{* * *}$ & -0.91 \\
Flexibility & 2.84 & 4.40 & & 1.23 & 1.12 & $-18.43^{* * *}$ & -1.32 \\
Technology usage & 2.97 & 4.45 & & 1.23 & 1.18 & $-17.00^{* * *}$ & -1.23 \\
Learning data & 2.63 & 4.20 & 1.34 & 1.17 & $-17.71^{* * *}$ & -1.25 \\
Differentiation & 2.60 & 4.44 & & 1.16 & 1.14 & $-22.86^{* * *}$ & -1.60 \\
Investigation & 3.16 & 4.29 & & 1.14 & 1.21 & $-13.39^{* * *}$ & -0.96 \\
Cooperation & 3.37 & 4.50 & 1.09 & 1.09 & $-14.39^{* * *}$ & -1.04 \\
Students cohesiveness & 4.18 & 4.75 & & 0.98 & 1.06 & $-6.67^{* * *}$ & -0.56 \\
Equity & 3.82 & 4.65 & & 1.17 & 1.15 & $-9.29^{* * *}$ & -0.72 \\
Learning experience & 3.51 & 4.60 & 1.15 & 1.13 & $-11.14^{* * *}$ & -0.96 \\
\hline
\end{tabular}

Note. ${ }^{* * *} p<.001$. 


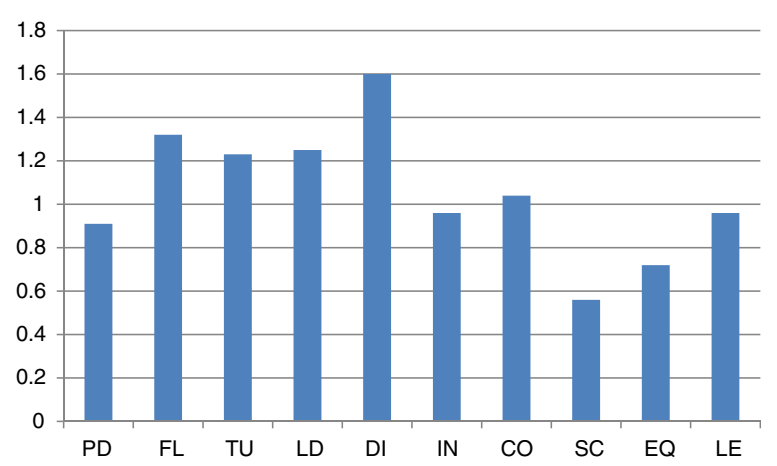

Figure 1 Cohen's d for both forms of the ten factors of the smart classroom survey.

The differences in perception of smart classroom between primary and secondary school students

The Mean, Standard Deviation (SD), and T-test for both primary and secondary school students' perception of smart classroom in both actual and preferred forms are respectively shown in Table 9 and Table 10.

Table 9 shows that except Learning Data, the scores in all the other scales of secondary school students are higher than those of primary students. There are significant differences in students' perception of the scales of Technology Usage, Learning Data, Students Cohesiveness, Equity, and Learning Experience in current situation.

But in preferred form, as shown in Table 10, there are not differences in perception of smart classroom between the primary and secondary school students. And the scores in scales such as Physical Design, Flexibility, Differentiation, Students Cohesiveness, and Equity of primary students are higher than secondary students.

\section{Discussion}

The feature of $\mathrm{SCl}$

This study employed the exploratory and confirmatory factor analysis to validate the psychometric structure of a new instrument for smart classroom-namely, Smart

Table 7 Summary of measurement scales of both female and male students' perception of smart classroom for actual forms

\begin{tabular}{|c|c|c|c|c|c|}
\hline \multirow[t]{2}{*}{ Factors } & \multicolumn{2}{|l|}{ Mean } & \multicolumn{2}{|l|}{ SD } & \multirow[t]{2}{*}{ T-test } \\
\hline & Female & Male & Female & Male & \\
\hline Physical design & 3.53 & 3.49 & 0.82 & 0.86 & 0.70 \\
\hline Flexibility & 2.84 & 2.84 & 1.21 & 1.23 & -0.20 \\
\hline Technology usage & 3.00 & 2.94 & 1.21 & 1.20 & 0.59 \\
\hline Learning data & 2.76 & 2.51 & 1.36 & 1.27 & $2.11^{* *}$ \\
\hline Differentiation & 2.58 & 2.61 & 1.11 & 1.16 & -0.15 \\
\hline Investigation & 3.19 & 3.13 & 1.04 & 1.08 & 0.56 \\
\hline Cooperation & 3.41 & 3.33 & 1.01 & 1.01 & 0.58 \\
\hline Students cohesiveness & 4.31 & 4.06 & 0.71 & 0.90 & $3.28^{* * *}$ \\
\hline Equity & 3.94 & 3.71 & 0.85 & 1.04 & $3.62^{* * *}$ \\
\hline Learning experience & 3.54 & 3.48 & 1.00 & 1.13 & 0.41 \\
\hline
\end{tabular}

Note. ${ }^{* *} p<.01,{ }^{* * *} p<.001$. 
Table 8 Summary of measurement scales of both female and male students' perception of smart classroom for preferred forms

\begin{tabular}{lllllll}
\hline Factors & \multicolumn{2}{l}{ Mean } & & \multicolumn{2}{l}{ SD } & T-test \\
\cline { 2 - 3 } & Female & Male & & Female & Male & \\
\hline Physical design & 4.49 & 4.35 & & 0.67 & 0.83 & 1.62 \\
Flexibility & 4.50 & 4.31 & & 0.76 & 0.94 & $2.26^{* *}$ \\
Technology usage & 4.47 & 4.43 & & 0.90 & 1.00 & 0.48 \\
Learning data & 4.29 & 4.12 & & 0.83 & 1.10 & 1.95 \\
Differentiation & 4.47 & 4.42 & & 0.83 & 0.92 & 0.33 \\
Investigation & 4.22 & 4.35 & & 0.97 & 0.95 & -1.14 \\
Cooperation & 4.53 & 4.48 & & 0.90 & 0.90 & 0.59 \\
Students cohesiveness & 4.83 & 4.68 & & 0.47 & 0.64 & $2.95^{* *}$ \\
Equity & 4.72 & 4.58 & & 0.53 & 0.75 & $2.40^{* *}$ \\
Learning experience & 4.69 & 4.51 & 1.31 & 0.81 & $2.08^{* *}$ \\
\hline
\end{tabular}

Note. ${ }^{* *} p<.01$.

Classroom Inventory (SCI). The SCI consists of critical aspects derived from the current instruments. Although some items were withdrawn by the instrumentation, these do not threaten the factor structure.

Based on the empirical results, the SCI is distinctive from existing technologyoriented learning environment instruments. First, the SCI redefines the physical appearance of the learning environment by incorporating additional factors as Physical Design and Flexibility. The factors of Physical Design and Flexibility differ from TICI's Audiovisual Environment, which emphasize more on spatial arrangement, and the adjustment of classroom environment parameters, like light and temperature. Second, the information technology used in classroom environment in SCI is tailored to the general technological usage in smart classrooms. They emphasize more diversified application of other digital devices besides computer, and classroom's access to Internet, such as "I can cooperate with somebody outside the classroom through Internet when doing assignment work". Third, the SCI considers the smart technological impacts to teaching and learning activities and learning experience according to the previous findings, and tailor to technology supportive learning scenarios in smart classroom, such as "the

Table 9 Summary of measurement scales of both primary and secondary students' perception of smart classroom for actual forms

\begin{tabular}{lllllll}
\hline Factors & Mean & & & SD & T-test \\
\cline { 2 - 3 } & Primary & Secondary & & Primary & Secondary & \\
\hline Physical design & 3.50 & 3.53 & & 0.80 & 0.93 & -0.44 \\
Flexibility & 2.79 & 2.95 & & 1.24 & 1.13 & -1.49 \\
Technology usage & 2.83 & 3.28 & & 1.19 & 1.15 & $-4.37^{* * *}$ \\
Learning data & 2.71 & 2.45 & & 1.35 & 1.18 & $2.25^{* *}$ \\
Differentiation & 2.59 & 2.62 & & 1.15 & 1.07 & -0.31 \\
Investigation & 3.12 & 3.25 & & 1.03 & 1.15 & -1.48 \\
Cooperation & 3.31 & 3.51 & & 0.99 & 1.06 & -0.94 \\
Students cohesiveness & 4.13 & 4.29 & & 0.82 & 0.85 & $-2.03^{* *}$ \\
Equity & 3.71 & 4.07 & & 0.99 & 0.88 & $-3.35^{* *}$ \\
Learning experience & 3.45 & 3.64 & & 1.08 & 1.06 & $-2.10^{* *}$ \\
\hline
\end{tabular}

Note. ${ }^{* *} p<.01,{ }^{* * *} p<.001$. 
Table 10 Summary of measurement scales of both primary and secondary students' perception of smart classroom for preferred forms

\begin{tabular}{lllllll}
\hline Factors & Mean & & & SD & T-test \\
\cline { 2 - 3 } & Primary & Secondary & & Primary & Secondary & \\
\hline Physical design & 4.51 & 4.21 & & 0.70 & 0.92 & 1.13 \\
Flexibility & 4.42 & 4.35 & & 0.81 & 1.01 & 0.79 \\
Technology usage & 4.42 & 4.51 & & 0.96 & 0.95 & -0.16 \\
Learning data & 4.19 & 4.22 & & 1.00 & 0.96 & -0.25 \\
Differentiation & 4.45 & 4.42 & & 0.90 & 0.84 & 0.13 \\
Investigation & 4.24 & 4.40 & & 0.95 & 0.98 & -1.11 \\
Cooperation & 4.45 & 4.61 & & 0.90 & 0.90 & -0.73 \\
Students cohesiveness & 4.76 & 4.73 & & 0.56 & 0.61 & 0.79 \\
Equity & 4.68 & 4.58 & & 0.61 & 0.82 & 1.74 \\
Learning experience & 4.56 & 4.69 & & 0.72 & 1.72 & -0.86 \\
\hline
\end{tabular}

devices and software help me to get hands-on experience with the learning objects or learning context". Overall, the SCI is verified as a parsimonious instrument for assessing the technology-rich smart classroom.

The factor of Learning Data is retrieved in the SCI. Some researchers indicated that smart classroom can give adaptive learning support to the student by detecting, recording, and analyzing the students' entire learning statuses (Dogan and Camurcu 2007; Zhang et al. 2009; Latham et al. 2012). Students' learning data is the basis for constructing learning model and giving the individualized learning diagnosis. The study indicates that massive learning data analysis is the key feature of smart classroom which is distinguished from the traditional computerized classroom.

The factor of Learning Experience is also retrieved in the SCI. Researches indicated that students have the positive attitude to the learning experience in smart classroom, for the smart technologies or smart devices give the students possibility to interact, communicate with learning content and learning object under the real and virtual combined learning context, and give the students possibility to be individually concerned (Özyurt et al. 2013; Yang et al. 2013). In the smart classroom students can get the unique learning experience, their learning interest and learning motivation are engaged by the open and authentic smart learning environment.

As shown in Table 4, the correlation coefficient between Technology Usage and other two factors as Learning Data and Differentiation are higher than 0.41. It confirms that the Technology Usage level plays an important role in the adaptive learning support for students in smart classroom. The correlation coefficient between Learning Data and other three factors for learning activities as Differentiation, Investigation, and Cooperation are higher than 0.48, which confirms that Learning Data are the basis for smart learning activities. Survey for the Actual form shows those students' perceptions of Flexibility, Technology Usage, and Learning Data are lower. It implies that in current situation, the core features of smart classroom are still not applied in classroom appropriately. However students are very eager for getting more targeted and personalized learning help in their own learning activities with the support of technology in smart classroom, which is reflected by Cohen's d value of Flexibility, Learning Data, and Technology Usage. 
Differed from Flexibility, Technology Usage, and Learning Data, one of the core factors of smart classroom, the Physical Design gets a relatively high score of 3.51 in Actual form. The study attributes that to the large amount of information technology infrastructure investments in primary and secondary schools in China during the past decade. Shenzhen is one of the most economically developed areas in China and Beijing is the capital of China. They accept a large amount of financial allocation on eeducation construction every year. Many schools in Shenzhen and Beijing have equipped with tablet PCs, interactive desks, and large surface interactive screens, which make them precede of smart schools pilot programs in China.

In current situation, students' perception of learning activities tends to be negative, especially in factor of Differentiation, which gets the lowest score of 2.6 among all of ten factors. The study attributes that to the traditional teacher-centered pedagogical theory and teaching practice still dominate the class in these schools, although they have been equipped with advanced software and hardware. The survey reflects that students expect for more individualized and active learning activities. It implies that China should pay more attention to pedagogical innovation and speed up the change to the student-centered learning models.

All students involved in the survey have had the learning experience in the technology-rich classroom, so the score of Learning Experience is above average level. And students in Shenzhen and Beijing are always affected by traditional culture of China like solidarity, and friendliness, so students' perception of Student Cohesiveness and Equity are much higher.

\section{The differences in perception of smart classroom of both gender and school settings}

The study finds that there are significant differences in students' perception of Student Cohesiveness and Equity in smart classroom between female and male students in both current and desired situations. The result indicates that female students are more sensitive to the student-student, and student-teacher relationships in the learning environments.

Although, the score in Learning Data is relatively low among all the ten scales, the female students are still having difference with the male students. The study attributes it to the female students are often study hard and pursue the good academic grades than the male students do in China. Even in current situation, the build of Learning Data is not perfect, but it still useful for female students' learning.

In the desired situation, the female and male students have differences in Flexibility, and Learning Experience. Actually, these two scales emphasize the students' psychological feeling of their interaction with the physical learning environment, learning devices, as well as learning activities in smart classroom. For example, "The classroom is climate controlled with localized temperature and humidity controls"., and "The devices and software are easy to use". The study also classified these two scales to the relationships in learning environment, namely human-space, human-machine relationships. The result further indicates that female students pay more attention to the varying relationships in smart classroom than male students. Therefore, in addition to the technical elements, the smart classroom design should increase more humane and emotional elements for students especially for the female students. 
As shown in Table 9, except Learning Data, the secondary school students have more positive attitude to current classroom situation than the primary school students. And there are significant differences in the scales of Technology Usage, Learning Data, Students Cohesiveness, Equity, and Learning Experience.

The secondary school students always have had the experience of integrating information technology into their learning activities when they were in primary schools. They accumulate more abundant technology usage experiences and more profound learning experience than primary school students. Comparing with the primary school students, the secondary students are more sophisticated in the studentsstudents relationship and the students-teachers relationship. So it is easy to interpret the differences in those scales of Technology Usage, Learning Experience, Students Cohesiveness, and Equity.

The difference in Learning Data is more complex. The score of "My parents can acquire my learning status in school from some apps or digital communication platforms easily" is 2.92 in primary school students and 2.66 in secondary school students. And the score of "I can find out my learning history such as my homework, and discussions using computers or other digital devices" is 2.76 in primary school students and 2.17 in secondary school students. The study finds that there are big gaps in these two questions of Learning Data between primary and secondary school students. Researchers think that the usages of learning data have to rely on the function of platform as well as the students' understanding of the application of learning data. Primary school students always use the simple function of the platform to support their learning according to their information literacy level, so they can acquire more intuitive feeling of learning data usage than secondary school students.

In the desired situation, all the scales of perception of smart classroom have no significant differences between primary and secondary school students. The result indicates that two groups have the similar expectations of the future smart classroom. The interesting phenomenon is the primary school students have more expectation of equipment, space design, and relationships in the future classroom, and the secondary school students pay more attention to deep learning activities and learning experience in the future smart classroom, which is shown in Table 10. The result infers the different demands in different age users, so the smart classroom should consider multi-level intelligence learning activities for each stage students within K12.

\section{Conclusion}

This study has developed the Smart Classroom Inventory (SCI) using data from primary and secondary schools in China. The results of validation support the fact that SCI has a parsimonious structure and sound psychometric properties. Ten factors consisting of 36 socio-psychosocial and physical items are included in SCI in order to assess students' perception of smart classroom in current and ideal situations.

The Physical Design, Flexibility, Technology Usage, and Learning Data have proved to be the core features for smart classroom environment, and they construct the basis for Differentiation, Investigation, and Cooperation learning activities, as well as the 
Learning experience. Students Cohesiveness and Equity will reflect some change in relationship of students and teachers in smart classroom.

Although the SCI is developed on the same schema as the existing digital classroom inventories, like TROFLEI, TICI, and CCEI, it highlights the most critical features of the smart classroom, which are shown in Table 11.

Through adding Physical Design, Flexibility, and Learning Experience, the SCI extends the content of System maintenance and change from the equipment of devices in the digital classroom to the interaction of human and learning environments. All the furniture, devices, and software in the classroom should be well designed to facilitate the students-centered learning and give the students and teachers vivid and convenient feelings during their teaching and learning process. The SCI adds the Learning Data to the inventory to emphasize the importance and the feasibility of Learning Data in the smart classroom. As without the usage of 1 to 1 digital devices, learning data which is the basis of learning analysis, was difficult to collect, storage, analyze, and apply to the teaching and learning activities before. And now in the smart classroom learning data will be the key for personal development.

Using SCI to assess the Actual and Preferred discrepancies of smart classroom learning environment finds there are significant differences in all of the ten factors. Students' perception of Differentiation learning is the largest actual-preferred discrepancies within the smart classroom learning environment. The factors of Flexibility, Technology Usage, and Learning Data follow. These suggest the importance of innovative application of the current information equipment, and schools should pay more attention to satisfying students' personalized learning demands.

The differences between the gender and between the school settings indicate that smart classroom should integrate both the technology and the humanities factors into the design and application of smart classroom, as well as design multi-level learning activities to satisfy the choice of students in difference ages.

In the future, the research will focus on optimization of the inventory, and apply the inventory to multi-cultural students and teachers for further validation.

Table 11 The comparison of $\mathrm{SCl}$ and existing digital classroom inventories

\begin{tabular}{lll}
\hline Trickett and moos schema & Existing inventories & SCI \\
\hline System maintenance and change & $\begin{array}{l}\text { Computer usage }{ }^{1}, \text { Audiovisual environment }^{2}, \\
\text { Technological enrichment }{ }^{2}, \text { Workspace environment }^{3}, \\
\text { Computer environment }\end{array}$ Visual environment $^{3}$, \\
Spatial environment
\end{tabular}

Note. ${ }^{1} \mathrm{TROFLEI},{ }^{2} \mathrm{TICl},{ }^{3} \mathrm{CCEI}$. 


\section{Competing interests}

The authors declare that they have no competing interests.

\section{Authors' contributions}

BL, SCK and GC designed the study. BL collected the items of the Smart Classroom Inventory (SCI) and carried out the survey. BL and SCK performed the statistical analysis. BL, SCK and GC worked out and finalized the manuscript. All authors read and approved the final manuscript.

\section{Acknowledgements}

This work was funded by the Chinese Ministry of Education Humanities and Social science Foundation under projects number 14YJC880025.

\section{Author details}

${ }^{1}$ School of Educational Technology, Beijing Normal University, Beijing, China. ${ }^{2}$ Department of Mathematics and Information Technology, The Hong Kong Institute of Education, Hong Kong, China.

Received: 1 October 2014 Accepted: 21 January 2015

\section{Published online: 12 February 2015}

\section{References}

JM Aldridge, JP Dorman, BJ Fraser, Use of multitrait-multimethod modelling to validate actual and preferred forms of the technology-rich outcomes-focused learning environment inventory (Troflei). Aus. J. Educ. Dev. Psychol. 4, 110-125 (2004)

DSG Carter, Knowledge transmitter, social scientist or reflective thinker: three images of the practitioner in Western Australian high schools. Theory Res. Educ. XVIII, 274-317 (1990)

C Chang, C Hsiao, Y Chang, Science learning outcomes in alignment with learning environment preferences. J. Sci. Educ. Technol. 20(2), 136-145 (2011)

E De Corte, L Verschaffel, C Masui, The CLIA-model: a framework for designing powerful learning environments for thinking and problem solving. Eur. J. Psychol. Educ. 19(4), 365-384 (2004)

B Dogan, AY Camurcu, Association rule mining from an intelligent tutor. J. Educ. Technol. Sys. 36(4), 433-447 (2007)

BJ Fraser, Research on classroom and school climate, in Handbook of research on science teaching and learning, ed. by DL Gabe (Macmillan, New York, 1994), pp. 493-541

NB Grady, DL Fisher, The educology of classroom environments and the quality of student learning. Int. J. Educol. 22(1/2), 73-83 (2008)

M Hall, A Ramsay, J Raven, Changing the learning environment to promote deep learning approaches in first-year accounting students. Account Educ. 13(4), 489-505 (2004)

$\mathrm{RH}$ Huang, YB Hu, JF Yang, GD Xiao, The function of smart classroom in smart learning age (in Chinese). OER 18(2), 22-27 (2012)

GJ Hwang, HC Chu, JL Shih, SH Huang, CC Tsai, A decision-tree-oriented guidance mechanism for conducting nature science observation activities in a context-aware ubiquitous learning environment. Educ. Technol. Soc. 13(2), 53-64 (2010)

A Latham, K Crockett, D McLean, A conversational intelligent tutoring system to automatically predict learning styles. Comput. Educ. 59, 95-109 (2012)

C Lemmon, SM Lui, D Cottrell, J Hamilton, Challenges to develop an interactive 3D virtual world for psychological experiments, in Proceedings of the European Conference on Games Based Learning, 2012, pp. 278-284

BP Li, SC Kong, Technology intelligence of the smart learning environment: a content analysis of publications in the past decade, in Proceedings of the 18th global Chinese conference on computers in education, May 26-30, Shangha, ed. by W Chen, X Gu, YT Wu, 2014, pp. 232-233

BP Li, SC Kong, G Chen, A study on the development of the smart classroom scale, in Emerging issues in smart learning, ed. by G Chen, V Kumar, Kinshuk, RH Huang, SC Kong (Springer Berlin Heidelberg, Berlin, 2014), pp. 45-52

YT Lin, YM Huang, SC Cheng, An automatic group composition system for composing collaborative learning groups using enhanced particle swarm optimization. Comput. Educ. 55, 1483-1493 (2010)

CF Lin, YC Yeh, YH Hung, RI Chang, Data mining for providing a personalized learning path in creativity: an application of decision trees. Comput. Educ. 68, 199-210 (2013)

M Liu, L Horton, J Olmanson, P Toprac, A study of learning and motivation in a new media enriched environment for middle school science. Educ. Technol. Res. Dev. 59, 249-265 (2011)

A Lizzion, K Wilson, R Simons, University students' perceptions of the learning environment and academic outcomes: Implications for theory and practice. Stud. High. Educ. 27, 27-51 (2002)

CE Loughlin, JH Suina, The learning environment: An instructional strategy (Teachers College Press, New York, 1982)

D Maor, BJ Fraser, Use of classroom environment perceptions in evaluating inquiry-based computer-assisted learning. Int. J. Sci. Educ. 18(4), 401-421 (1996)

CP Newhouse, Development and use of an instrument for computer-supported learning environments. Learn. Environ. Res. 4(2), 115-138 (2001)

CP Newhouse, Teachers' responses and classroom learning environments associated with student access to portable computers, PhD thesis, Curtin University of Technology, 1998

Ö Özyurt, H Özyurt, A Baki, B Güven, Integration into mathematics classrooms of an adaptive and intelligent individualized e-learning environment: implementation and evaluation of UZWEBMAT. Comput. Hum. Behav. 29, $726-738$ (2013)

S Rahman, S Mokhtar, Structural relationship of learning environment, learning approaches, and generic skills among engineering students. ASS 8(13), 280-290 (2012). doi: 10.5539/ass.v8n13p280

P Ramsden, Student learning and perceptions of the academic environment. High. Educ. 8(4), 411-427 (1979)

$P$ Ramsden, A performance indicator of teaching quality in higher education: the course experience questionnaire. Stud. High. Educ. 16, 129-149 (1991) 
JFD Silva, FJ Restivo, An intelligent mashup learning environment with social interaction, in Proceedings of the European Conference on e-Learning, 2009, pp. 759-766

The Free Library: Technology rich Kansas classrooms (2007), http://www.thefreelibrary.com/Technology+rich+Kansas+ classrooms.-a0160714506. Accessed 12 Feb 2015

EJ Trickett, RH Moos, Social environment of junior high and high school classrooms. J. Educ. Psychol. 65(1), 93-102 (1973)

A Whiteside, DC Brooks, JD Walker, Making the case for space: three years of empirical research on learning environments. (Educaseuse Quarterly, 2010), http://www.educause.edu/ero/article/making-case-space-three-yearsempirical-research-learning-environments. Accessed 13 Feb 2015

W Wu, HP Chang, CJ Guo, The development of an instrument for a technology-integrated science learning environment. Int. J. Sci. Math. Educ. 7, 207-233 (2009)

JC Yang, YL Lin, Development and evaluation of an interactive mobile learning environment with shared display groupware. Educ Technol Soc 13(1), 195-207 (2010)

Y Yang, H Leung, L Yue, Generating a two-phase lesson for guiding beginners to learn basic dance movements. Comput. Educ. 61, 1-20 (2013)

SS Yau, SKS Gupta, F Karim, SI Ahamed, Y Wang, B Wang, Smart classroom: enhancing collaborative learning using pervasive computing technology, in Proceedings of ASEE Annual Conference and Exposition: Staying in Tune with Engineering Education, 2003, pp. 13633-13642

DB Zandvliet, The physical and psychosocial environment associated with classrooms using new information technologies-A cross-national study, PhD thesis, Curtin University of Technology, 1999

L Zhang, M Gillies, K Dhaliwal, A Gower, D Robertson, B Crabtree, Facilitating online role-play using an Al actor and emotionally expressive characters. IJAIED 19, 5-38 (2009)

JT Zhao, Research university faculty perceptions of smart classroom technologies (Intellectual Property Publishing House, Beijing, 2008), pp. 3-15

\section{Submit your manuscript to a SpringerOpen ${ }^{\circ}$} journal and benefit from:

- Convenient online submission

- Rigorous peer review

- Immediate publication on acceptance

- Open access: articles freely available online

- High visibility within the field

Retaining the copyright to your article 